\title{
Intersectoral Mobilization in Child Development: An Outcome Assessment of the Survey of the School Readiness of Montreal Children
}

\section{Isabelle Laurin ${ }^{1, *}$, Angèle Bilodeau ${ }^{2, \dagger}$, Nadia Giguère ${ }^{3, \dagger}$ and Louise Potvin ${ }^{2, \dagger}$}

1 Montreal Department of Public Health, 1301 Sherbrooke East, Montreal, QC H2L 1M3, Canada

2 School of Public Health, University of Montreal, PO Box 6128 Station Centre-ville, Montreal, QC H3C 3J7 Canada; E-Mails: angele.bilodeau@umontreal.ca (A.B.); louise.potvin@umontreal.ca (L.P.)

3 Jeanne-Mance Health and Social Services Center Research Center, 1250 Sanguinet Street, Suite 477, Montreal, QC H2X 3E7, Canada; E-Mail: nadia.giguere.jmance@ssss.gouv.qc.ca

$\dagger$ These authors contributed equally to this work.

* Author to whom correspondence should be addressed; E-Mail: ilaurin@santepub-mtl.qc.ca; Tel.: +1-514-528-2400 (ext. 3971)

Academic Editor: Jerry D. Marx

Received: 16 October 2015 / Accepted: 2 December 2015 / Published: 8 December 2015

\begin{abstract}
In 2006, the department of public health in Montreal, Quebec, Canada, conducted the Survey of the School Readiness of Montreal Children. After unveiling the results in February 2008, it launched an appeal for intersectoral mobilization. This article documents the chain of events in the collective decision-making process that fostered ownership of the survey results and involvement in action. It also documents the impacts of those findings on intersectoral action and the organization of early childhood services four years later. The results show that the survey served as a catalyst for intersectoral action as reflected in the increased size and strength of the actor network and the formalization of the highly-anticipated collaboration between school and early childhood networks. Actors have made abundant use of survey results in planning and justifying the continuation of projects or implementation of new ones. A notable outcome, in all territories, has been the development of both transition-to-kindergarten tools and literacy activities. The portrait drawn by the research raises significant issues for public planning while serving as a reminder of the importance of intersectoral mobilization in providing support for multiple trajectories of child preschool development.
\end{abstract}


Keywords: population-level intervention; community mobilization; child development; school readiness; collective decision-making; knowledge transfer; early childhood services; public planning; early development instrument

\section{Introduction}

The importance of providing support for child development during the first years of life has been abundantly reinforced over the past two decades [1-3]. All children do not start out in life with the same opportunities or the same social capital [4-6]. Poverty places some children in contexts that prevent them from developing at the same rate as others, and this reality becomes apparent when they start school [7-9]. The differences observed in children constitute a form of inequality that can be reduced by intelligent public policies that support families in precarious socio economic situations $[4,10]$.

To obtain a better understanding of the spheres of development necessitating preventative action, researchers developed the Early Development Instrument (EDI), a population measure of child development [11]. The tool, developed in Ontario during the 1990s, is now used throughout Canada and other countries to evaluate children's levels of development when they start school. It is also designed to serve as a planning tool for mobilizing networks of stakeholders to effect transformations in living conditions, resources and services [12].

In the wake of the pan-Canadian movement for child development, the department of public health of the Montreal Health and Social Services Agency in the province of Quebec, Canada, launched the Montreal Summit Initiative on School Readiness in 2008, as a follow-up to its Survey of the School Readiness of Montreal Children [13,14]. The survey used the EDI, and revealed that $35 \%$ of Montreal children were vulnerable in at least one developmental area when they started school. It found considerable differences between Montreal neighbourhoods, with results ranging from 23\% to 43\% [15]. The objective of the Summit Initiative was to identify child-development related needs on the Island of Montreal and to improve service provision by mobilizing intersectoral partners concerned with early childhood services at the local level of 12 Health and Social Services Centres ${ }^{1}$ (HSSC) as well as on a regional level. The initiative also fell under the broader objectives of Quebec's provincial public health program for 2003-2012 [16], which, following the World Health Organization's example, made community development one of the province's key public health intervention strategies for promoting health and reducing social inequalities in health [17]. Despite the popularity of this type of community-level intervention, little research has been done on the processes involved in those interventions. Consequently, there is underproduction of theoretical knowledge and underuse of those practices $[18,19]$.

To offset the situation, this article presents the collective decision-making process used during the Montreal Summit Initiative on School Readiness to transform early-childhood service organization in Montreal. The article also documents processes of change in early childhood service organization and actor mobilization after EDI data were released. Although many mobilization initiatives have been

1 In Quebec, Health and Social Services Centres are public organizations that provide front-line health and social assistance services, such as home care for elderly or disabled persons, prenatal classes and early childhood services. Each of the 12 HSSC's in Montreal is associated with a specific territory that determines the population it serves. 
carried out in Canada since the early 2000s [20-22], no study has documented the impact of these surveys on collective planning in communities. A survey of nine Canadian provinces was conducted [23], but it presents general observations and not processes that lead to changes in communities. The study by Laurin et al. is informative in this regard; however the scope of those results is limited since the study focused on only one Montreal neighbourhood [18].

The current study was undertaken to document the processes by which the Survey of the School Readiness of Montreal Children fostered actor mobilization in all districts of Montreal. This article documents (1) the chain of events in the collective decision-making process that fostered ownership of the survey results and actor mobilization; and (2) the ongoing effects on intersectoral action and service organization throughout Montreal four years later.

\section{Methods}

\subsection{Theoretical Framework}

Actor-network theory (ANT), a social theory concerned with how actions by networks of actors are constituted and operate, provided the general framework for analysis of the population health initiatives arising out of the Summit Initiative intersectoral action and community mobilization. This theory is recognized as being a conceptually useful tool for appraising complex situations and analysing the production of change [19]. ANT perceives such initiatives as complex systems of action, i.e., socio-technical networks (STN), which generate social reproduction/transformation processes in achieving certain end goals $[19,24]$. These process-generating networks are described as socio-technical due to their mobilization of social actors, knowledge (both scientific and experiential), and goods [25-27]. Social actors in such networks are characterized by their social position, identity, interests, and the issues that mobilize them in the situation under study. Setting up action networks requires constant translation that consists in generating clear, meaningful links toward action among heterogeneous entities involved in a situation [28]. The general purpose of such systems of action is the orientation of social transformations at their level, and the response to situations deemed problematic.

In such networks of multi-sectoral actors, decisions are not the product of a single actor or of a response to an isolated situation, but rather of a process shaped by the actions and interactions of influential actors, both inside and outside a system of action, within a specific context. Out of these actions and interactions arise different events (what happens) that constitute the relevant data for the study of such processes. The decision-making process is thus comprised of a chain of events out of which the decision is built $[24,29]$. When public institutions play a role in these decision-making processes (e.g., as financial backers), the primary modus operandi used by these actor networks to construct decisions remains programmed action (planning, implementation, sustainability and reflexivity), exercised pragmatically in light of the different perspectives and interests involved [30,31]. In such systems, programmed action is necessarily a process that occurs at a specific time and place and in a specific context. It is a dynamic entity that both transforms and is transformed by this context. Its means of action are the creation, reconfiguration and extension of the socio-technical network that allows for the input of actors, goods, and new knowledge. 


\subsection{Design}

The research design was a three-year multiple-case study [32] monitoring the activities of the regional committee and six local committees during both the Montreal Summits phase (February 2008-May 2009), and the post-summit phase (June 2009 until the end of research in December 2011). The systems of action (actor networks and interventions) mobilized around the issue of school readiness constituted the principal unit of analysis. This is an interpretive study in that data are interpreted in light of the theoretical framework described earlier. The study looks at processes and their outputs as they occurred in situ, beyond the researchers' control.

\subsection{Participants}

The study focuses on one regional and six local systems of action selected from among the 12 HSSCs in Montreal, based on two criteria: (1) having a high percentage and number of vulnerable children in terms of school readiness, based on survey data; and (2) ensuring regional representation. Sociodemographic representation of the six districts reflects a wide range of situations: some are very ethnically diverse, some are very poor, and some comprise large zones of poverty even though they are considered middle-income areas. The regional and local systems of action comprise intersectoral actors involved in preparing children for school.

\subsection{Data Sources and Collection Methods}

One community organizer from each of the six districts under study, together with one representative from the regional committee were asked and agreed to participate as research partners. They passed on to the research team all administrative documentation relevant to the project. Three methods of data collection were used: (1) note-taking during non-participant direct observation of regional events and meetings of both regional $(n=9)$ and local $(n=24)$ committees; (2) document analysis of the minutes of the meetings of regional and local summit organizing and monitoring committees $(n=24)$ as well as of other local early childhood collaborative bodies $(n=140)$, and of administrative and planning documents $(n=271)$; (3) semi-structured individual and small group (2 to 3 people) interviews, as a complement to the analysis of administrative documentation, conducted one $(n=38)$, and two $(n=24)$ years later. At the regional level, semi-structured individual interviews were carried out with 14 committee members from the health, education, daycare, community, municipal, charitable and immigration sectors. At the local level, semi-structured interviews were conducted with each of the community organizers from the six territories, accompanied by one or more representatives from other sectors in accordance with the organizer's wishes.

\subsection{Analysis}

Data processing consisted of the production of a database comprised of pertinent excerpts from the administrative documents, interviews, and observation field notes, coded according to the study's theoretical framework. Two matrices were used to organize and analyze data. The first describes the composition of socio-technical networks - organizational actors (e.g., HSSC, schools, and daycares) and collective actors (e.g., committees), mobilized goods and knowledge. The second classifies 
decision-making events by programmed action: planning, implementation, sustainability and reflexivity. Data were organized chronologically to reconstruct a posteriori the principal chain of events constituting the collective process of programmed action. Triangulation of data from the various sources was used to ensure the validity of results.

The analysis focused on identifying the actor networks involved in the Summit Initiative, the knowledge and goods or resources they mobilized, and the role played by survey data. A second focus was the chain of events composing the summit and post-summit decision-making processes that showed how choices were made and decisions taken, and the outcomes on services described by the actors.

The results were validated at a sharing activity in April 2011 during which regional actors or those involved in the six local cases discussed the results for the 2008-2009 period that had ended with a regional summit. For the post-summit period (2009-2011), result validation and sharing activities were not possible due to the very large number of local actors in the various sectors involved. Rather, we opted to validate survey data, established with administrative sources and observation, through interviews with the actors concerned. Triangulation of documentary sources and observation led us to retain, in the matrices, data that could not be validated in interviews, even though administrative documents demonstrated the existence of those survey data.

\section{Results}

The appeal for action made by the department of public health of the Montreal Health and Social Services Agency (DPH) following the release of the survey data led to the extension and consolidation of actor networks involved in early childhood issues, both regionally and locally. These networks of actors took ownership of the survey data, planning and implementing actions they judged pertinent and feasible. Two important collective decisions were characteristic of this process. First, at the end of the 15-month summit phase, regional and local actors collectively managed to transform child school readiness into an important social issue and called for mobilization for action. Second, during the post-summit period, local solutions were structured around the idea that child development issues or problems of school readiness could be reduced through the increased availability and accessibility of services for vulnerable children in the community. The following analysis presents the chain of key events and the actors involved in elaborating these decisions.

\subsection{The Collective Decision-Making Process during the Summits: The Transformation of Survey} Results into an Important Social Issue

A series of seven sequential and occasionally overlapping events provided the framework for the decision-making process during the summit phase. It is important to note that while preparing the Survey of the School Readiness of Montreal Children to be conducted in 2006, the survey's instigators met with the principal early childhood actors in the 12 HSSC territories to inform them of the survey objectives and the proposed mobilization approach. This tour also served as an opportunity to consult communities on the establishment of territorial divisions smaller than HSSC territories, more representative of actual living environments, and more useful from an intervention perspective.

Table 1 presents information on the Survey of the School Readiness of Montreal Children and the Montreal Summit Initiative on School Readiness (2005-2008) that chronologically lists some of the events that ensued. 
Table 1. Montreal Summit initiative on School Readiness.

\begin{tabular}{|c|c|c|c|}
\hline & Stakeholders involved & Accomplishments & Important dates \\
\hline $\begin{array}{l}\text { Survey en } \\
\text { route pour } \\
\text { l'école! }\end{array}$ & $\begin{array}{l}\text { A survey conducted by the DPH } \\
\text { Partners: Lucie and André Chagnon } \\
\text { Foundation } \\
\text { - The } 5 \text { Montreal school boards } \\
\text { - Research unit on children's psychosocial } \\
\text { - maladjustment (GRIP) } \\
\text { - Centre } 1,2,3 \text { Go! } \\
\text { - Social Development Canada }\end{array}$ & $\begin{array}{l}\text { - Met with school boards to enlist their collaboration in collecting data. } \\
\text { - Met with the main early childhood stakeholders in each of Montreal's } 12 \text { HSSC to } \\
\text { inform them of the survey objectives and of mobilization efforts } \\
\text { - Defined the new divisions in Montreal (more significant for communities) into } 101 \\
\text { neighbourhoods } \\
\text { - Collected data from educators } \\
\text { - Produced and released a series of reports that present a portrait of the school } \\
\text { readiness of Montreal children using the Early Development Instrument (EDI) to } \\
\text { measure the five domains of readiness }\end{array}$ & $\begin{array}{l}2005 \\
\text { February } 2006 \\
\text { February } 2008\end{array}$ \\
\hline Local summits & $\begin{array}{l}\text { Led by: the } 12 \text { HSSC, in collaboration with: } \\
\text { local partners } \\
\text { Support from: DPH }\end{array}$ & $\begin{array}{l}\text { - Organized and carried out } 12 \text { local summits (1 per HSSC territory), each of which } \\
\text { reached over } 100 \text { people } \\
\text { - Fruitful exchanges that fostered a shared interpretation of the situation, leading to } \\
\text { identification of a number of challenges and avenues for solutions regarding } \\
\text { resource development, service organization and ways to work with children and } \\
\text { families } \\
\text { - Wrote } 12 \text { synthesis reports on discussions held during the summits (with the help of } \\
\text { notes taken by the DPH during various activities) } \\
\text { - Defined three action priorities for each territory }\end{array}$ & Fall 2008 to Spring 2009 \\
\hline $\begin{array}{l}\text { Montreal } \\
\text { Summit }\end{array}$ & $\begin{array}{l}\text { Comité régional pour une action concertée } \\
\text { en développement de l'enfant }\end{array}$ & $\begin{array}{l}\text { - Organized and carried out two theme days (the role of parents and distinctive } \\
\text { characteristics of Montreal) that brought to the fore specific issues prior to the local } \\
\text { summits } \\
\text { - Conducted iterative analyses of information emerging from local summits to ensure } \\
\text { the Montreal Summit is in line with local concerns } \\
\text { - Carried out the Montreal Summit } \\
\text { - Promoted the three priorities established by the HSSC and their partners }\end{array}$ & $\begin{array}{l}2008-2009 \\
28 / 05 / 2009\end{array}$ \\
\hline $\begin{array}{l}\text { Overview of } \\
\text { the process }\end{array}$ & $\mathrm{DPH}$ & $\begin{array}{l}\text { - Disseminated a synthesis document outlining the main concerns expressed by a } \\
\text { majority of partners throughout the summits initiative } \\
\text { - Disseminated a video of the highlights of the Montreal Summit on school readiness } \\
\text { (28 May 2009) }\end{array}$ & Summer 2009 \\
\hline
\end{tabular}




\subsubsection{Publication of Survey Results-February 2008}

In February 2008, the DPH published the results of the Survey of the School Readiness of Montreal Children. Given the finding that $35 \%$ of Montreal children were vulnerable in at least one developmental area when they started school, it was stated that the time of "one-size-fits-all" solutions was past, and that it was important to look at what was working locally and to fine-tune the interventions. Concurrently, it appealed for cooperation among the various actors concerned with preparing children for school (health, education, and daycare services networks, community groups, the City and philanthropic groups). It was at this moment that the Summit Initiative was announced. The Initiative would use Montreal's public health infrastructure comprised of the DPH and the 12 HSSC, which would assume responsibility for implementing the initiative at the local level from February 2008 to May 2009. At the end of the 12 local summits — one per HSSC territory — and to conclude the process, a regional event would be held to which all Montreal early childhood actors would be invited.

\subsubsection{Involvement of Regional Intersectoral Partners in the Summit Process - March 2008}

In March 2008, the DPH called on its regional partners to join it in the summit process. A regional intersectoral collaborative body (RIC) was created bringing together partners from the health care network, education, daycare, community and charitable organizations, and from the Ministry of Immigration. City of Montreal officials (from the library network and the social development sector) asked to be included in order to participate in the collective discussion, as they considered themselves as having an informal educator role in early childhood support. The RIC's mandate included support for the summit process as well as ownership of the survey data. This included reflecting on the issues raised by the researchers in their report, that is, accessibility and quality of childcare services and kindergarten for four-year-olds; the capacity of public policies and programs to lift families out of poverty and reduce social inequalities; and convergent and complementary actions.

\subsubsection{Act 7 and the Creation of the Fund for Early Childhood Development-March 2008}

In March 2008, only a few brief weeks after the survey results had been released, the Government of Quebec announced in its budget the introduction of Bill 7, creating the Fund for Early Childhood Development in partnership with a private foundation. The fund, for which one of the justifications was the survey results, was intended to inject CAD $\$ 400$ million over 10 years into local initiatives targeting children aged five and under living in poverty. The Government of Quebec then launched a public hearing in which 19 organizations took part. The Government concluded that most organizations agreed with the fund. However, a press release was immediately issued by a federation of family associations rectifying the Government's conclusions and stating that only seven organizations stood in support of the fund, while eight groups were calling for either a moratorium on the bill or its withdrawal. The bill was nevertheless adopted in the fall of 2009, and the public-philanthropic partnership launched its activities in the spring of 2010. 


\subsubsection{Theme Days and Discussions in Preparation for the Summits-2008-2009}

Other issues in addition to the ones submitted to actors by the RIC in the survey report emerged as a result of the mobilization, and were initially explored by the RIC in preparatory discussions for the summits. The RIC organized two theme days, one devoted to the role of parents in service development, and the other to ethnic diversity, population mobility, and poverty-unique Montreal concerns. In the actors' opinion, it was vital that discussions of the provision of services take into account the fact that every five years $20 \%$ of the population of Montreal changes, while $43 \%$ moves to a different neighbourhood. These activities primarily brought together actors from the health care network in addition to RIC members.

A discussion day, this time reserved solely for members of the RIC, permitted representatives of the Ministry of the Family (childcare services) and Ministry of Education to present their programs and overviews of the services they provided. However, the issues of childcare accessibility and quality and the development of kindergarten for four-year-olds were not specifically addressed in order to avoid undermining the spirit of dialogue, as partners were of different opinions as to the type of educational setting best suited to four-year-olds. The RIC also held another internal discussion on the day-to-day difficulties faced by community organizations.

These discussion days led to the creation of working groups, made up of RIC members and operating outside regular meetings, to explore certain topics in greater detail in preparation for the regional summit.

\subsubsection{DPH Support for the Organization of Local Summits-2008-2009}

Certain HSSCs perceived the mandate of organizing local summits as a command issued by the DPH while others, having been told of the survey in 2005, were ready and willing to mobilize their community. The HSSCs generally acknowledge that it was in their mandate to organize such a process in their community. However, they also recognized that the organization of the summit required leadership-sharing with the community and, with the exception of one territory, established organizing committees made up of intersectoral partners.

The DPH provided the 12 HSSCs with support, notably in the form of funding. At their request, it produced a guide for the organization of the events, suggesting strategic actors to invite and proposing a procedure to be followed and topics of discussion (Samson, 2008). To help actors assimilate the data, researchers put several tools at their disposal: (1) detailed reports by school board (5), school (203), HSSC and neighbourhood (12), a regional report, and a summary report; (2) a map of public early childhood programs in local territories; and (3) a summary table of school readiness and socioeconomic indices by HSSC territories and neighbourhoods.

In preparation for the local summits, the researchers made themselves available for two pre-summit meetings in each territory to discuss the survey data. These meetings permitted the researchers to learn of some criticisms of the survey, provoked notably by the somewhat alarmist coverage it had received in certain newspapers, and to prepare a response. They also provided an opportunity to discuss some of the surprising results in territories considered to be advantaged where the proportion of vulnerable children was high. During these discussions, a number of organizing committees asked the researchers to provide additional analyses for their HSSC, for children from immigrant backgrounds for example, 
or to map the schools that had or had not participated in the survey to provide them with a better understanding of unexpected results.

\subsubsection{The Local Summits—2008-2009}

The 12 local summits were held over a period of 10 months, and brought together approximately 100 people each. The events took various forms depending on the territory. The researchers presented the survey data as well as the issues they had identified. Some territories invited additional speakers while others presented complementary information such as the territory's socio-demographic profile and resources, or held forums with parents on preparing children for school. All offered a form of collective reflexivity through discussion workshops. There was greater mobilization in certain territories either due to their possessing more highly-developed collaborative practices, or because school readiness had been a local concern for several years, or because the results of the survey were so striking they gave rise to a sense of urgency. However, local summits in all territories attracted a diverse range of actors, including parents. RIC actors also took part, several in more than one territory, thereby ensuring local-regional alignment.

It goes without saying that ownership of the results took different forms in each territory, but the picture presented generally corresponded to actors' observations: (1) the data presented by neighbourhood revealed previously unsuspected or little mentioned zones of poverty and school readiness vulnerability; (2) the data presented in terms of the numbers of vulnerable children rather than simple percentages brought to light new priority intervention areas; and (3) the data on available public resources showed that some territories were particularly underequipped given their needs. This was true for example of reduced-contribution childcare: in two out of three HSSC territories, the percentage of available spaces was under 50\%. Furthermore, although the Education Act of 1997 stipulates that all children from underprivileged backgrounds must have the possibility of attending kindergarten beginning at age four, 12 of the 60 schools serving the most disadvantaged areas in Montreal did not offer kindergarten for four-year-olds despite being located in areas where the proportion of at-risk children was higher than the Montreal average.

The numerous concerns raised by the picture presented were coloured by the socio-demographic characteristics of the territory, its history of mobilization, the intersectoral representativeness of the actors involved, and the range of services provided to families. However, in several territories, the survey re-opened the old divisive debate between schools and daycares as to where four-year-olds belong ${ }^{2}$. It also shone a light on the lack of formal links between early childhood resources and schools and the impact of this situation on children's transition to school. Bill 7, not yet adopted into law at the time of the summits, also raised a host of fears in all the territories. Several actors denounced the social public-philanthropic partnership that would touch on areas of public policy. Others questioned the political will to target children living in poverty while still others feared their voices would not be heard and that new orientations would upset the dynamics of local consultation and the configuration of services. Finally, the results raised parental doubts about the measures to be taken and concerns

2 In Quebec, most children start school with full-time kindergarten at age five. Children from underprivileged backgrounds have the possibility of attending part-time kindergarten beginning at age four. Twenty percent of Quebec children attend part-time kindergarten. 
about the risk of stigmatizing certain children. Some feared decision-makers were moving towards early schooling by making kindergarten mandatory as of age four.

\subsubsection{Preparation and Holding of the Montreal Summit—Spring 2009}

The Montreal Summit was a regional event that brought the process to an end after 10 months of on-going local mobilization. Aware that local actors would want to have a voice at the summit, the RIC made the rounds beforehand to receive approval for its proposed program, and asked each of the 12 HSSC to write out three possible avenues for improving services. However, the RIC's program also offered the additional regional benefit of exploring issues affecting all territories, inspired by the working groups generated by the theme days.

The Montreal Summit of May 2009 brought together a variety of actors, of which the most numerous were the HSSCs, followed by community organizations and schools. The advantage of a regional forum was reflected in the question put to participants, i.e., what regional and provincial mechanisms should be used to ensure a better fit between the needs of Montreal families and available services given the challenges posed by the diversity and mobility of Montreal families as well as the difficulty of reaching so-called "isolated" families. For each aspect of the question, a video produced with parents was presented, followed by a panel comprised of parents and early childhood professionals.

Local actors had high expectations for the RIC at the regional summit. They had mobilized to hold the local summits and proposed possible solutions, and they expected organizers to produce a summary of local demands and make commitments in line with the demands. The regional summit proved unsatisfactory on this level. No such summary was produced and no investment was announced in situ in response to their concerns. Local actors saw no sign of the RIC's promised regional advantage, and had an impression of déjà-vu.

The regional summit concluded with a joint declaration by the RIC members in which they made a commitment to continue their efforts in favour of child development. In the aftermath of the summits, local actors said they were relieved no new program had been announced for top-down implementation. Otherwise, they said, what good would all their efforts have been if the outcome had been decided ahead of time?

Finally, the DPH produced a summary of all the written submissions produced during the process at both local and regional levels [33]. The analysis linked issues and solutions related to school readiness. Its first priority was to stress the necessity of taking action on family living conditions and the need to respect the fact that some families would first want to obtain support to meet their basic needs. It supported the adoption of non-blaming approaches with parents geared towards the creation of opportunities for families to come together rather than screening. Finally, it strongly emphasized the urgency of establishing formal links between early childhood resources and schools. It deplored the fact that most teachers had little knowledge of the preschool trajectories of the children they welcome into kindergarten. Parents are under a great deal of social pressure to ensure their children are "ready" when they start school, without really knowing what that means. The analysis served to guide the RIC in the development of its action plan. 


\subsection{The Post-Summit Collective Decision-Making Process: Developing a Solution Based on Early}

\section{Childhood Services in the Community}

The events that laid the foundation for the collective decision-making process regarding the development of solutions occurred simultaneously at regional and local levels following the regional summit of May 2009. The events involving the actor network will be examined first, followed by those concerned with solution implementation.

\subsubsection{Regional and Local Actor Networks in the Post-Summit Period}

In the two years following the regional summit, the 14 members of the RIC focused on giving the committee a clear identity, defining its mandate, and developing a strategic plan. They set up a coordination committee to ensure shared leadership among members and combat fears that had been present since the beginning of the process that the DPH would exercise too much influence over decisions. The RIC made changes to its composition to consolidate its partnership with other regional collaborative bodies, especially ones focusing on student retention and academic success. However, it was also faced with the withdrawal of one community actor that cited the actor's position against social public-private partnerships and its uneasiness with the fact that one of the RIC's main financial contributors was the product of such a partnership.

The post-summit period was marked by flagging collaboration between local and regional levels, as a result of regional actors' lack of support for local communities. Due to the importance of taking local concerns into account in establishing its guidelines, the RIC polled the 300 regional summit participants in the spring of 2010 regarding the primary courses of strategic action it should adopt. Following this sounding-out process, in June 2011 the RIC unveiled its strategic plan for 2010-2015 permitting regional actors to reconnect with local counterparts. In 2011 and 2012, the RIC conducted two projects to encourage renewed contact. The Constellation project was aimed at pooling and sharing experience and knowledge regarding difficult-to-reach families, while the objective of the Basic Services Basket project was to identify what parents and both local and regional actors would like to receive in terms of resources and basic services throughout the entire Montreal area. It addressed the problem of the unequal distribution of services among Montreal territories mentioned at the summits, as well as the issue of family mobility.

However, local actors' expectations of the regional level were high and remained unmet. On the one hand, they wanted the RIC to exercise political influence in situations where local entities were powerless. For example, they expected the RIC to appeal to public decision-makers to curb the proliferation of non-government-subsidized private daycares due to the absence of regulations governing such daycares and the lack of training of the educators who worked in them. Local actors also expected their regional counterparts in the RIC to promote actions designed to improve family living conditions. However, the position adopted by the RIC with regard to exercising political influence ensured it would never place its members in a difficult position, as they also had to answer to ministries responsible for public policies and programs. The regional actors concluded that they did not have the means to initiate action on these questions and agreed instead to join in lobbying efforts by other bodies. On the other hand, local actors requested that the regional level strive to ensure greater harmonization of early childhood 
funding. Such an expectation would undoubtedly be difficult to meet because any solution would signify a loss of autonomy for donors in terms of program definition and accountability. The arrival on the scene of actors issuing from public-philanthropic partnerships, with still more accounting mechanisms, did nothing to simplify the situation.

After the 2009 summits, local actors initially continued their work in the local committees set-up to organize the summits. After approximately a year, discussions were held in all territories, marking the dissolution of these committees whose work was then taken up by other local collaborative bodies in which the actors continued to work towards the priorities adopted. At the end of data collection in 2011, traces of the Summit Initiative were visible in all HSSC local action plans which served as the basis for continuation of community mobilization on this issue. The summits' influence was also apparent in certain local action plans that had previously focused on 6- to 12-year-olds but now incorporated activities targeting children ages 0 to five years. This was true for school boards, boroughs, and philanthropic partners.

These commitments signify the extension of the early childhood actor network, notably through connections with school boards, ardently desired by actors for many years, formalizing schools' desire to become involved. Henceforth, school principals had the approval of their regional and provincial counterparts to engage fully in early childhood discussions. The municipality, which the RIC had invited to participate from the very beginning, improved its relations with the community by developing connections with organizations. Due to their new outreach mandate, libraries were able to take an active role in consultations and participate in numerous intersectoral projects.

\subsubsection{Survey and Summit Initiative Outcomes for Service Organization}

Decision-making is primarily sectoral at government and regional levels. Actors identified a number of advances in which the contributions made by the survey and the Summit Initiative were apparent. The Government of Quebec's creation of the Fund for Early Childhood Development as part of a public-philanthropic partnership is unquestionably an important outcome. It allows for local funding of joint action and support for regional and interregional bodies that conduct knowledge- and practice-sharing activities, such as the RIC's Constellation and Basic Services Basket projects. In 2009, the Education Ministry launched its strategies for student academic success, which included pre-school actions involving the early childhood network. It used survey results, among other things, to establish selection criteria for territories targeted by its early literacy program. Finally, in 2010, it joined its counterparts in the health and family sectors to coproduce a guide to provide support for children's transition to school. On a regional level, the health, childcare, municipal and philanthropic sectors introduced additional resources, using survey data to better target the territories in which they should be implemented.

The process was also seen to have significant local outcomes, reflecting the DPH's desire, as stated at the opening of the summits, to take its cue from what works locally and further refine its interventions. Joint planning by local collaborative bodies was the principal modus operandi for collective decision-making to guide and coordinate the actions of public, public-philanthropic, and community actors. As in the problematization phase, collective reflection activities played an important role in the decision-making process during planning. Less documentation is available on the implementation or continuation of new services due to the study's short duration. Some of the outcomes took the form of 
initiatives on child language, motor and social development. Others were more general in nature, such as the creation of additional daycare spaces, parent-child workshops, a drop-in daycare, support for new arrivals, access to a reduced rate for city-run activities, and the establishment of a family outreach centre or social paediatric services. Of these, transition-to-school and literacy activities will be examined more closely as they were implemented in all territories. The full range of outcomes can be found in two general audience publications produced for the actors $[13,14]$.

Transition-to-school actions were the result of the redefinition of preschool ( 0 to 5 years) guidelines adopted by the Ministry of Education. These actions include the use of school-transition tools. The aim of these tools was to provide a descriptive portrait of the child's overall development to foster discussion between community or childcare organizations and schools. They were also designed to ensure intervention continuity between networks. The tool is completed by the child's educator in the spring and given to the parents who are responsible for transmitting it to the school. To meet the needs of children not in childcare, school boards and community organizations offer parent-child workshops and educational kindergarten-preparation day camps. The camps have undergone considerable growth since 2008. In addition to the participation of the school and childcare communities, the implementation of new activities involves actors from community, health and municipal organizations.

The newly implemented early literacy programs are the product of a Ministry of Education emergent literacy program and the clear commitment of libraries to off-site programming. Librarians are present in the field and lead activities in a variety of different contexts, such as city parks and social housing complexes. Now books can be borrowed not only at libraries; but in community organizations, daycares, and parks as well, not to mention in the street through bookmobiles. The activities financed by the Ministry's early literacy program focus on integrating reading into children's and family activities. An example of such an activity might be setting up a reading corner in a HSSC waiting room. Books are also presented as gifts at immunization sessions and perinatal home visits.

The post-summit collective decision making process was devoted to developing local solutions specifically adapted to community needs. In a characteristic chain of events, the consolidation of the regional and local action networks, the provision of additional resources by government and regional sectoral decision-makers, and the ability of these networks to carry out on-going planning of the priorities established during the summit phase, would appear to have provided as the combined ingredients for the collective decisions.

\section{Discussion}

The initial focus of our study was to understand how a social health survey report can impel actors to mobilize to improve early childhood resources and services in communities. By using the actor-network theory, we wanted to establish how the problem under study - school readiness - was problematized in regional and local networks. We wanted to understand what encouraged mobilization, the processes by which the actor network expanded and was consolidated, the use it made of survey data, and the type of answers actors were able to supply. The study also enabled us to document precisely the issues raised by the EDI and the actions that ensued in the field of early childhood. 


\subsection{The Expansion and Consolidation of the Actor Network}

Several of the quality attributes associated with collective action and decision-making processes were observed in the initiative under study here [34-36]. Such a broad mobilization process must be able to count on a system of action able to support it [37]. In this instance, Montreal's public health system, with its regional administration and 12 HSSCs provided this structure. Mobilization occurred within a dense, multi-sectoral network with a history of collaborative practices in the field of early education. We know that if a network is to be productive, it requires genuine, credible leadership [38]. Other actors in the network acknowledged that Montreal's public health system provided this leadership. If a collective decision-making process is to bring about change in a system of action, new knowledge and resources must be mobilized [35]. In this regard, in addition to survey data for small neighbourhood areas being made available in non-technical language, the DPH also provided logistical and financial support so HSSCs could organize local summits to foster ownership of and collective reflection on the results. To stimulate reflection and steer it towards public policies, the DPH took it upon itself to examine the survey results in light of the issues it had presented to the communities. It extended a more formal invitation to RIC members to present their opinions on these issues, thus ensuring they would be included on the Montreal summit agenda at the end of the data ownership process. Thus, the Montreal initiative succeeded in building the issue of school readiness into an important social issue by combining evidence with a knowledge-sharing process designed for a diverse target audience, which constituted the optimal conditions for making early childhood part of the political agenda [39]. Problematized in this manner, the issue of children's school readiness entreated new actors to engage in and endorse new roles in the search for solutions. The notion of translation in ANT appropriately reflects the process observed.

Even though a culture of intersectoral collaboration in early childhood was already present in three-quarters of Canadian municipalities well before the beginning of data collection using the EDI, the contribution of the results obtained and the accompanying mobilization acted as a catalyst for intersectoral action [23]. Montreal was no exception. While the Summit Initiative was part of consultation dynamic already well-established in municipalities, the consultation was transformed by the survey. First, because the survey results made it possible to quantify the situation, they gave child development a visibility and importance that was more compelling than before. This had an impact on early childhood actors who felt empowered to call attention to the situation of children under the age of five and their parents in other collaborative bodies to which they belonged concerned with social development, immigration, or school dropout for example. Next, in all territories the formation of intersectoral committees for local summit organization and follow-up resulted in the extension and consolidation of networks of partners. Finally, as a result of the actors having made actions targeting the transition from daycare to school a priority in the post-summit period, the two communities were brought closer together. All of these local collaborative transformations were fostered by the implementation of a regional intersectoral collaborative body at the time of the publication of the survey results, indicating a genuine commitment on the part of regional sectoral actors to claiming ownership of the results and following up with concrete action. For example, if boroughs and schools were as involved at the local level, it was because decision-makers in these sectors had made decisions accompanied by adequate funding to enable them to be agents of change. Thus, as observed by Janus [23], the results of Canada-wide 
surveys provided the raw material for creating dialogue and shifting decision-makers' focus to early childhood intervention. This was even truer of schools [40], as was observed in Montreal.

\subsection{Survey Results as Planning Tools}

Janus [23] observed that in many Canadian municipalities the activities established following the surveys were implemented in small territories, such as neighbourhoods, boroughs, or school districts. The same tendency was observed in Montreal, which is not surprising as actors were provided with a map of results by neighbourhood, HSSC territory, school board, and school. In addition to the practical knowledge they already possessed, the actors had everything, including socio-economic indicators and a map of public services, necessary to improve actions in priority areas. These areas were designated as such in part because of the survey results, but also because they were in outlying areas, lacked services, and had a high proportion of low-income and/or recently immigrated families. The outcome was new projects and services as well as the continuation of pre-existing programs, which, in light of the discussion initiated by the summits, were shown to be more than pertinent. Prior to the 2006 survey, intersectoral decision-makers undoubtedly had other sources of data at their disposal on which to base their decisions, from the Ministry of Education or of the Family for example, but the population data produced by the DPH served to as a bridge between different sources by shedding new light on the entire Montreal population of five-year-olds by territory. Thus, as in other Canadian provinces, the survey results were combined with other information for use as key criteria for the allocation of early childhood resources and of spaces in reduced-contribution childcare.

\subsection{Outcomes for Action}

It is more difficult to make a comparison with other Canadian municipalities with regard to outcomes for action as these are dependent on pre-existing services and, more broadly, on the public policies in place in the different provinces. Quebec's family policies stand apart in many ways from those in the rest of Canada, especially the universal daycare policy which has no equivalent in the other provinces, as well as the child assistance benefit and paid parental leave which are much more generous than elsewhere [41]. Nonetheless, of the outcomes inventoried on a Canada-wide basis by Janus [23], the most frequent were those associated literacy and designed to support cognitive and language development. A predominance of this type of projects was also observed in Montreal, as demonstrated by the early literacy activities. Just as important, transition-to-school activities also experienced a considerable boom, echoing the efforts made in several other Canadian municipalities to bridge the gap between the early childhood network and schools.

\section{Conclusions}

The preschool life of Quebec children is neither unique nor comprised of a single trajectory: some attend daycare, others start kindergarten at the age of four, and others remain at home until school starts for everyone at the age of five. In such a context, relying on intersectoral action ensures the provision of a greater range of services touching the various spheres of child development, better visibility in the community, and increased accessibility. 
The results of this study show that considerable effort is being made locally to develop a range of services adapted to families' needs. Nonetheless, they raise important issues around public planning and call into question the ability of local communities to organize to meet the multiple needs of families and children. Central to the challenges they face is promoting equity in child development by striking a balance between local services and guaranteed access for families to equivalent services in all territories. This is in line with the recommendations made by Hertzman who, supported by a decade of EDI-based research, is ardently campaigning for universal access to early childhood services [42].

\section{Acknowledgments}

This study was made possible by a grant from the Canadian Institutes of Health Research (CIHR), 2009-2012 - Population Health Intervention Research Initiative.

\section{Author Contributions}

Angèle Bilodeau and Isabelle Laurin, as co-principal investigators, contributed to the design of the study, the interpretation of the results and were principally involved with writing up the manuscript. Nadia Giguère was involved carrying out fieldwork and analysis. Louise Potvin contributed to the design of the study and the preparation of the manuscript.

\section{Conflicts of Interest}

The authors declare no conflict of interest.

\section{Abbreviations}

EDI: Early Development instrument;

DPH: Department of public health of the Montreal Health and Social Services Agency;

HSSC: Health and Social Services Centers;

RIC: regional intersectoral collaborative body.

\section{References}

1. Ron Haskins, Irwin Garfinkel, and Sara McLanahan. "Introduction: Two-generation mechanisms of child development." Helping Parents Helping Children: Two-Generation Mechanisms: The Future of Children 24 (2014): 3-13.

2. Nina Howe, and Larry Prochner. "Introduction." In Recent Perspectives on Early Childhood Education and Care in Canada. Edited by Nina Howe and Larry Prochner. Toronto: University of Toronto Press, 2014, pp. 1-11.

3. Margaret Norrie McCain, John Fraser Mustard, and Kerry McCuaig. Le Point sur la Petite Enfance 3: Prendre des Decisions, Agir (Early Years Study 3: Making Decisions, Taking Action). Toronto: Margaret and Wallace McCain Family Foundation, 2011.

4. Miles Corak. "Income Inequality, Equality of Opportunity, and Intergenerational Mobility." Journal of Economic Perspectives 27 (2013): 79-102. 
5. Aadrie Kusserow. American Individualisms: Child Rearing and Social Class in Three Neighborhoods. New York: Palmgrave Macmillan, 2004.

6. Sarah Theule Lubiensky. "Celebrating Diversity and Denying Disparaties: A Critical Assessment." Educational Researcher 32 (2003): 30-38.

7. Bruce Bradbury, Miles Corak, Jane Waldfogel, and Elizabeth Washbrook. "Inequality in Early Childhood Outcomes." In From Parents to Children: The Intergenerational Transmission of Advantage. Edited by John Ermisch, Markus Jäntti, Jane Waldfogel and Liz Washbrook. New York: Russell Sage Foundation, 2012, pp. 87-119.

8. Neeraj Kaushal. "Intergenerational Payoffs of Education." Helping Parents Helping Children: Two-Generation Mechanisms-The Future of Children 24 (2014): 61-78.

9. Valerie E. Lee, and David Burkam. Inequalities at the Starting Gate: Social Background Differences in Achievement as Children Begin School. Washington: Economic Policy Institute, 2002.

10. Annie McEwen, and Jennifer Stewart. "The Relationship between income and children's outcomes: A synthesis of Canadian evidence." Canadian Public Policy 40 (2014): 99-109.

11. Magdalena Janus, and Dan R. Offord. "Development and Psychometric Properties of the Early Development Instrument (EDI): A Measure of Children's School Readiness." Canadian Journal of Behavioural Science 39 (2007): 1-22.

12. Magdalena Janus, Sally Brinkman, Erid Duku, Clyde Hertzman, Robert Santos, Joanne Schroeder, Mary Sayer, and Cindy Walsh. The Early Development Instrument: A Population-based Measure for Communities - A Handbook on Development, Properties, and Use. Hamilton: MacMaster University, 2007.

13. Isabelle Laurin, Angèle Bilodeau, Nadia Giguère, and Anouk Lebel. Montreal Summits on School Readiness: Impacts on Mobilization. Focus on ...Intersectoral Action. Number 1. Montréal: Centre de Recherche Léa-Roback sur les Inégalités Sociales de Santé, 2014.

14. Isabelle Laurin, Angèle Bilodeau, Nadia Giguère, and Anouk Lebel. "Montreal Summits on School Readiness: Impacts on Service Organization." Focus on...Intersectoral Action. Number 2. Montréal: Centre de Recherche Léa-Roback sur les Inégalités Sociales de Santé, 2014.

15. Isabelle Laurin, Sylvie Lavoie, Danielle Guay, Laurence Boucheron, Danielle Durand, and Nathalie Goulet. "Enquête sur le Développement des Enfants Montréalais à leur Entrée à l'école (Survey of the school readiness of Montreal children)." Santé Publique 24 (2012): 7-21.

16. Ministère de la Santé et des Services Sociaux. "Programme National de Santé Publique 2003-2012. Mise à Jour 2008 (Quebec Public Health Program, 2003-2012: Update for 2008).” Available online: http://www.quebecenforme.org/media/1387/programme_national_de_sante_publique_2003-2012.pdf (accessed on 4 December 2015).

17. Wilfried Kreisel, and Yasmin von Schirnding. "Intersectoral action for health: A cornerstone for health for all in the 21st Century." World Health Statistics Quarterly 51 (1998): 75-78.

18. Isabelle Laurin, Angèle Bilodeau, and Sébastien Chartrand. "Maturité scolaire et mobilisation communautaire: Étude rétrospective dans un quartier montréalais (School readiness and community mobilization: A retrospective study of a Montreal neighborhood)." Canadian Journal of Public Health 103 (2012): S32-38.

19. Louise Potvin, Sylvie Gendron, Angèle Bilodeau, and Patrick Chabot. "Integrating social theory into public health practice." American Journal of Public Health 95 (2005): 591-95. 
20. Franklin Kutuadu, and Lori Baugh Littlejohns. The School Readiness of Red Deer's Kindergarten Children: A Preliminary Report on the Results of the Early Development Instrument (EDI). Red Deer: Early Development Instrument (EDI), 2009.

21. Michael Quenell, and Kathryn Smart. Understanding the Early Years Regina Community Mapping Report. Regina: UEY Regina, 2010.

22. Mothercraft. "Early Development Instrument (EDI) 2010/11 Toronto Results (2011)." Available online:http://www.mothercraft.ca/assets/site/docs/resource-library/EDI/reports/201011_Toronto EDIReport.pdf (accessed on 4 December 2015)

23. Magdalena Janus. Early Development Instrument: "From Results to Action Survey" Report. Hamilton: Offord Centre for Child Studies, McMaster University, 2013.

24. Louise Potvin, and Sherry Bisset. "There Is More to Methodology than Method." In Health Promotion Evaluation Practices in the Americas: Values and Research. Edited by Louise Potvin and David V. McQueen. New York: Springer, 2008.

25. Michel Callon. "Éléments pour une sociologie de la traduction (Some Elements of a Sociology of Translation).” L'année Sociologique 36 (1986): 169-208.

26. Michel Callon. "Introduction." In La Science et ses Réseaux. Genèse et Circulation des Faits Scientifiques. Edited by Éditions La Découverte and Michel Callon. Paris: Éditions La Découverte, 1988, pp. 7-33.

27. Bruno Latour. Changer de Société, Refaire de la Sociologie (Changing Societies, Rethinking Sociology). Paris: Éditions La Découverte, 2006.

28. Madeleine Akrich, Michel Callon, and Bruno Latour. "Sociologie de la traduction." In Textes Fondateurs. Paris: École des Mines de Paris, 2006.

29. Pierre Pluye, Louise Potvin, and Jean-Louis Denis. "La pérennisation organisationnelle des projets pilotes en promotion de la santé (The organizational perpetuation of health promotion pilot projects)." Ruptures Revue Transdisciplinaire en Santé 7 (2000): 99-113.

30. William Dab. "Réflexions sur les défis de la programmation en santé (Thoughts on the Challenges of Health Programming)." Promotion et Éducation 36 (2005): 169-208.

31. Louise Potvin, Angèle Bilodeau, and Sylvie Gendron. "Trois conceptions de la nature des programmes: Implication pour l'évaluation de programmes complexes en santé publique (Three perspectives on the nature of programs: Implications for the assessment of complex public health programs).” The Canadian Journal of Program Evaluation 26 (2012): 91-104.

32. Robert K. Yin. Case Study Research. Thousand Oaks: Sage, 1994.

33. Isabelle Laurin, Isabelle Samson, Sylvie Lavoie, Danielle Durand, and Laurence Boucheron. Les Sommets sur la Maturité Scolaire-Document Synthèse de la Démarche Effectuée en 2008-2009 (The Summits on School Readiness: Summary Report on the 2008-2009 Process). Montreal: Direction de Santé Publique-Agence de la Santé et des Services Sociaux de Montréal, 2010.

34. Agence de Santé Publique du Canada. Au Croisement des Secteurs-Expériences en Action Intersectorielle, en Politique Publique et en Santé (Crossing Sectors-Experiences in Intersectoral Action, Public Policy and Health). Ottawa: Agence de Santé Publique du Canada, 2007.

35. Angèle Bilodeau, Marilène Galarneau, Michel Fournier, and Louise Potvin. "L'Outil diagnostique de l'action en partenariat: Fondements, élaboration et validation (Diagnostic Tool for Partnership Action)." Canadian Journal of public Health 102 (2011): 298-302. 
36. Roz D. Lasker, Elisa S. Weiss, and Rebecca Miller. "Partnership synergy: A practical framework for studying and strengthening the collaborative advantage.” Millbank Quarterly 79 (2001): 179-205.

37. John M. Bryson, Barbara C. Crosby, and Melissa Middleton Stone. "The Design and implementation of Cross-Sector Collaborations: Propositions from the Literature." Public Administration Review 66 (2006): 44-55.

38. Henri Amblard, Philippe Bernoux, Gilles Herreros, and Yves François Livan. Les Nouvelles Approches Sociologiques des Organisations. Paris: Éditions du Seuil, 1996.

39. Aletha C. Huston. "From research to policy and back." Child Development 79 (2008): 1-12.

40. Janet Mort. The Early Development Instrument (EDI) in British Columbia: Documenting Impact and Action in Schools, Communities and Childhood Development. Vancouver: Council for Early Child Development, 2009.

41. Jane Jenson. "Early childhood learning and care: The route to meeting the major challenges." Policy Options 27 (2006): 55-58.

42. Clyde Hertzman. "Peut-on parler «d'équité dès le départ» au Canada (Is there equity from the start in Canada)?" ISPP Pop Nouvelle 22 (2010): 6-8.

(C) 2015 by the authors; licensee MDPI, Basel, Switzerland. This article is an open access article distributed under the terms and conditions of the Creative Commons Attribution license (http://creativecommons.org/licenses/by/4.0/). 